NBER WORKING PAPER SERIES

\title{
NEW PRODUCTS, QUALITY CHANGES AND WELFARE MEASURES COMPUTED FROM ESTIMATED DEMAND SYSTEMS
}

\author{
Aviv Nevo \\ Working Paper 8425 \\ http://www.nber.org/papers/w8425 \\ NATIONAL BUREAU OF ECONOMIC RESEARCH \\ 1050 Massachusetts Avenue \\ Cambridge, MA 02138 \\ August 2001
}

This paper was motivated by discussions with Zvi Griliches. I am grateful to Lanier Benkard, Ariel Pakes, Amil Petrin, two anonymous reviewers, the Editor, and seminar participants at the Berkeley-Stanford IOfest, UC Berkeley, UC Davis, University of Chicago, NBER Productivity workshop and NBER/CRIW conference for comments and suggestions. I wish to thank Ronald Cotterill, the director of the Food Marketing Policy Center in the University of Connecticut, for providing the price and quantity data used in this study. Financial support from the UC-Berkeley Committee on Research Junior Faculty Fund is gratefully acknowledged. The views expressed herein are those of the authors and not necessarily those of the National Bureau of Economic Research.

(C) 2001 by Aviv Nevo. All rights reserved. Short sections of text, not to exceed two paragraphs, may be quoted without explicit permission provided that full credit, including (C) notice, is given to the source. 
New Products, Quality Changes and Welfare Measures

Computed from Estimated Demand Systems

Aviv Nevo

NBER Working Paper No. 8425

August 2001

\begin{abstract}
$\underline{\text { ABSTRACT }}$
This paper examines the construction of a price index based on an estimated demand system. In principle the method examined can produce a price index that accounts for introduction of new products and quality changes in existing products. However, I isolate two key assumptions that have to be made in order to interpret the demand estimates into welfare measures. Using estimates of a brand-level demand system for ready-to-eat cereal I demonstrate the empirical importance of the assumptions. For the data I use, depending on the interpretation of the demand estimates, a price index can range between a $35 \%$ percent increase over the five years examined to a $2.4 \%$ decrease.
\end{abstract}

\author{
Aviv Nevo \\ Department of Economics \\ 549 Evans Hall \#3880 \\ University of California \\ Berkeley, CA 94720-3880 \\ and NBER \\ nevo@econ.berkeley.edu
}




\section{INTRODUCTION}

Accurate measurement of changes in the cost of living is one of the major tasks of applied economics. The results have implications for a variety of issues ranging from aggregate growth, industry productivity, real wages and poverty rates. The Consumer Price Index (CPI) Commission, appointed by the Senate Finance Committee, found that the current CPI overstates the cost of living by about 1.1 percentage points (Boskin et al. 1996). The Commission also pointed to several causes of this bias. Two of concerns raised, introduction of new products and quality changes (Gordon and Griliches, 1997), have been studied using estimated demand systems to evaluate welfare implications (for example, see Trajtenberg, 1989, 1990; Pakes, Berry and Levinsohn, 1993; Hausman, 1996, 1997, Petrin 1998).

This paper attempts to construct a price index that accounts for new product introductions and quality changes. The basic idea is straight forward. I estimate a demand system, which allows for the inclusion of new products and accounts for quality changes. Next, I use the estimates to construct a measure of changes in consumer welfare, which can be converted to a price index. However, in order to construct the welfare measure I show that one has to make assumptions about the interpretation of the estimation results. In particular, the researcher has to take a stand on the interpretation of (1) time dummy variables, if these are included in the regression (as they usually are), and of (2) the error-terms. Consider an estimated positive time trend (or dummy variable). There are at least two reasons why the demand for a product could increase. The product could have improved, in which case, everything else being equal, consumer welfare increased. On the other hand, it is possible that the alternatives got worse. Both of these interpretations are consistent with an estimated positive time effect, and if the purpose of the estimation is to compute own- and crossprice elasticities then separating them is not important. But they have different implications for consumer welfare.

An additional assumption has to be made regarding the residual from the estimation. If the error-term represents sampling error then we want to use the "average" demand curve for the analysis. But in the analysis below I use aggregate data in which case it is unlikely that the error-term 
is driven by sampling error (Berry, Levinsohn and Pakes, 1995). Instead the error-term includes product characteristics, which are unobserved by the econometrician but valued by consumers. Therefore, the residual should be included in the welfare analysis. But when performing the welfare computation should the residual be allowed to vary between periods or be held fixed? The answer, once again, depends on interpretation. If a change in the residual reflects a change in tastes (in the sense of Fisher and Shell, 1972) then the answer is no: the residual should not be allowed to vary in the welfare analysis. On the other hand if the residual captures unobserved quality changes it should be allowed to vary.

The rest of this paper discusses these two assumptions. In Section 2 I present the problem in the context of a discrete choice model. It is important to note that the points made below are not specific to this model, and are more general. The main claim is that neither of the above interpretations is identified from the price and quantity data used to estimate the demand system. Using data for ready-to-eat cereal and estimates of a demand system (taken from Nevo, 2001) I present, in Section 3, the empirical importance of the various assumptions. I show that if one wants to produce a price index that accounts for new brands and quality changes, depending on which assumptions are chosen, the results range from a $35 \%$ increase in the real price of cereal over 5 years, to a $2.4 \%$ price decrease. For the data used here the assumption regarding the time trend is more important than the assumption on the error-term, and explains almost all of this range. This might not always be the case.

Given this wide range I argue that common practice should include reporting this range. In cases, like here, where the range is wide I claim that researcher should be clear about the assumptions made and justify them based on prior knowledge. I point to situations where different sets of assumptions are more reasonable.

\section{THE MODEL}

I demonstrate my point in the context of a random coefficients discrete choice model of demand. The problems outlined below are not specific to this model; As I show below they have 
parallel in a "classic" demand model. Furthermore, similar issues arise when computing a price index based on a so called index formula. I focus on the discrete choice model for two reasons. First, this model has gained popularity lately and has been used in a variety of situations. Second, the somewhat more structural nature of the model (in particular the error-term) allows one to think about the problem more conceptually.

\subsection{An Empirical Model of Demand}

Suppose we observe $t=1, \ldots, T$ markets, each with $i=1, \ldots, M_{t}$ consumers, who are offered $j=1, \ldots, J_{t}$ brands. For simplicity we can think of $t$ as indexing time. The conditional indirect utility of consumer $i$ from product $j$ at time $t$ is

$$
v_{i j}^{t}=x_{j}^{t} \beta_{i}^{*}-\alpha_{i}^{*} p_{j}^{t}+\xi_{j}^{t}+\varepsilon_{i j}^{t} \equiv V_{i j}^{t}+\varepsilon_{i j}^{t},
$$

where $x_{j}^{t}$ is a vector of $K$ observable product characteristics, $p_{j}^{t}$ is the price of product $j$ at time $t$, assumed common to all consumers, $\xi_{j}^{t}$ is the valuation of unobserved (by the econometrician) product characteristics, and $\varepsilon_{i j}{ }^{t}$ is a mean zero stochastic term. Finally, $\left(\alpha_{i}^{*} \beta_{i}^{*}\right)$ are $K+1$ individual specific coefficients.

I model the distribution of consumers taste parameters for the characteristics as

$$
\left(\begin{array}{c}
\alpha_{i}^{*} \\
\beta_{i}^{*}
\end{array}\right)=\left(\begin{array}{l}
\alpha \\
\beta
\end{array}\right)+\Pi D_{i}+\Sigma \tau_{i}, \quad \tau_{i} \sim N\left(0, I_{K+1}\right),
$$

where $D_{i}$ is a $d \times 1$ vector of demographic variables, $\Pi$ is a $(K+1) \times d$ matrix of coefficients that measure how the taste characteristics vary with demographics, and $\Sigma$ is a scaling matrix. This specification allows the individual characteristics to consist of demographics that are observed, denoted $D_{i}$, and additional characteristics that are unobserved, denoted $\tau_{i}$, for which a normal distribution is assumed.

In principle, this specification allows for wealth effects since equation (1) allows the marginal utility from income, $\alpha_{i}$, to vary by individual, and equation (2) allows these coefficients to vary with demographics, one of which could be current income. In reality if the price of the product is small relative to current income one can assume that these coefficients do not change as 
a result of price changes. Both in order to simplify the presentation, and since my empirical example examines ready-to-eat cereal that satisfies the requirement that price is much lower than income, for the rest of the paper I assume no wealth effects. ${ }^{1}$

The specification of the demand system is completed with the introduction of an "outside good"; the consumers may decide not to purchase any of the brands. The indirect utility from this outside option is

$$
v_{i 0}^{t}=\xi_{0}^{t}+\varepsilon_{i 0}^{t} \equiv V_{i 0}^{t}+\varepsilon_{i 0}^{t} .
$$

Consumers are assumed to purchase one unit of the good that gives the highest utility. This implicitly defines the set of unobserved variables that lead to the choice of good $j$. Given assumptions on the distribution of the unobserved variables the model can be estimated with aggregate data (Berry, 1994; and Berry, Levinsohn and Pakes, 1995).

Various distributional assumptions on the unobserved variables would lead to different discrete choice models. For example, assuming $\alpha_{i}=\alpha$ and $\beta_{i}=\beta$ for all $i$ and $\varepsilon_{i j}{ }^{t}$ is distributed i.i.d. with a Type I extreme value distribution, we get the well-known (Multi-nominal) Logit model. The problems with the own- and cross-price elasticities implied by this model have been well documented (for example see McFadden 1981, or Berry Levinsohn and Pakes, 1995). Furthermore, the Logit model is also problematic for evaluating the welfare effects of economic changes (Petrin, 1998).

\subsection{Welfare Evaluation of Economic Changes Using Discrete Choice Models of Demand ${ }^{2}$}

A consumer's well-being will increase as a result of a price change if and only if $u_{i}\left(p^{t}, w\right)-u_{i}\left(p^{t-1}, w\right)>0$, where $u_{i}(\cdot)$ is consumer's $i$ indirect utility function, $p^{t}$ and $p^{t-1}$ are the prices before and after the change, respectively, and $w>0$ is the consumer's income. In order to

\footnotetext{
${ }^{1}$ This assumption does not drive any of the results, and although the details are slightly different the exercise below can be repeated for products where wealth effects are significant. Note, that this assumption still allows income to impact choice as a demographic variable, like age or education.

${ }^{2}$ This section reviews well-known definitions from welfare economics and shows how they apply to the model used here. For further discussion see, for example, Mas-Colell, Whinston and Green (1995) or Small and Rosen (1981).
} 
express the welfare change in monetary terms a particular class of indirect utility functions are used. These are constructed from the expenditure function and are called money metric. Using an arbitrary price vector, $\bar{p} \gg 0$, define $e\left(\bar{p}, u_{i}(p, w)\right)$. This function gives the expenditure the consumer needs to reach the utility level $u_{i}(p, w)$ when prices are $\bar{p}$. Thus, the consumer is better off if and only if

$$
e\left(\bar{p}, u_{i}\left(p^{t}, w\right)\right)-e\left(\bar{p}, u_{i}\left(p^{t-1}, w\right)\right)>0 .
$$

Furthermore, the left-hand side of equation (3) provides a monetary measure of the change in consumer welfare. This measure is important if we want to aggregate the change in welfare over several consumers, or if we want to compare to changes in producers profit.

In principal any price vector $\bar{p}$ can be used to construct the measure in equation (3). A natural choice is $p^{t-1}$, which leads to the welfare measure suggested by Hicks (1939): the equivalent variation $(\mathrm{EV}){ }^{3}$ The $\mathrm{EV}$ is the change in consumer wealth that would be equivalent to the change in consumer welfare due to the price change (expressed in monetary terms). Let $u_{i}{ }^{t}=u_{i}\left(p^{t}, w\right)$ then

$$
\mathrm{EV}_{\mathrm{it}}=e\left(p^{t-1}, u_{i}^{t}\right)-e\left(p^{t-1}, u_{i}^{t-1}\right)=e\left(p^{t-1}, u_{i}^{t}\right)-e\left(p^{t}, u_{i}^{t}\right)
$$

This measure will be negative when the consumer's well-being decreases as a result of the change, and positive when it increases. Note, that the utility is not held constant between the two periods but income is, i.e., $w=e\left(p^{t-1}, u_{i}^{t-1}\right)=e\left(p^{t}, u_{i}^{t}\right)$. Two ways to think about EV is (1) that it measures the difference in expenditure needed to achieve different utility levels in the two periods facing the initial prices; or (2) that it measures the difference in expenditure required for achieving the second period utility when faced with the two different price vectors. ${ }^{4}$

As shown by McFadden (1981) and Small and Rosen (1981), for the model presented in the

\footnotetext{
${ }^{3}$ An alternative choice is $p^{\mathrm{t}}$, which leads to the compensated variation $(\mathrm{CV})$. Due to the assumption on no wealth effects these two are equal.

${ }^{4}$ The equivalent variation can also be represented in terms of the compensated (Hicksian) demand curves:$$
\mathrm{EV}_{\mathrm{i}}\left(p^{t-1}, p^{t}, w\right)=\int_{p^{t}}^{p^{t-1}} h\left(p, u_{i}^{t}\right) d p
$$

where $h(\cdot \cdot)$ is the compensated demand curve. In words, the EV is equal to the area between $p^{\mathrm{t}-1}$ and $p^{\mathrm{t}}$ and is to the "left" of the compensated demand curve associated with the utility level $u^{\mathrm{t}}$. Due to the assumed lack of wealth effects, this is equal to the area "left" of the compensated curve associated with the utility level $u^{\mathrm{t}-1}$, as well as to uncompensated Marshallian consumer surplus.
} 
previous section the EV variation of individual $i$ is given by

$$
\mathrm{EV}_{\mathrm{it}}=\frac{u_{i}^{t}-u_{i}^{t-1}}{\alpha_{i}}
$$

where $u_{i}^{t-1}$ and $u_{i}^{t}$ are the (unconditional) indirect utilities in periods $t-1$ and $t$, i.e., $u_{i}^{t}=\max _{j} v_{i j}^{t}$. The measure of total consumer welfare is given by

$$
E V \equiv M \int \mathrm{EV}_{\mathrm{it}} d P^{*}(D, \tau, \varepsilon)=M \int \mathrm{EV}_{\mathrm{it}} d P_{D}^{*}(D) d P_{\tau}^{*}(\tau) d P_{\varepsilon}^{*}(\varepsilon)
$$

where $M$ is the total mass of consumers and $P^{*}(\cdot)$ are distribution functions. An assumption of independence of $D, \tau$ and $\varepsilon$ implies the equality

The integral in equation (5) can be computed in several ways. First, we could simulate draws from the distribution of the unobservable variables, $\varepsilon, v$ and $D$, for each triplet compute the value of the integrad, $\mathrm{EV}_{\mathrm{it}}$, and compute the (weighted) average of all the draws (Pakes, Berry and Levinsohn, 1993). Although intuitive, this approach is an inefficient way to compute the value of this integral. If the marginal utility of income is fixed for each individual (i.e., it does not vary as a result of the price change we are evaluating), then an alternative is to use the derivation of McFadden (1981) to integrate analytically the extreme value distribution of $\varepsilon$. In which case the integral in equation (5) is given by

$$
M \int \frac{\ln \left[\sum_{j=0}^{J_{t}} \exp \left(V_{i j}^{t}\right)\right]-\ln \left[\sum_{j=0}^{J_{t-1}} \exp \left(V_{i j}^{t-1}\right)\right]}{\alpha_{i}} d P_{\tau}^{*}(\tau) d P_{D}^{*}(D)
$$

If the marginal utility of income varies with the event that we are measuring, then the computation is more complex (McFadden, 1995).

The EV can be converted into a price index by finding the factor by which we have to multiply all prices in the base period in order to get the same welfare impact as computed by equation (6). Formally, we have to solve for $\varphi_{t}$ such that

$$
M \int\left(e\left(p^{t}, u_{i}^{t}\right)-e\left(\varphi^{t} \cdot p^{t-1}, u_{i}^{t}\right)\right) d P_{D}^{*}(D) d P_{\tau}^{*}(\tau) d P_{\varepsilon}^{*}(\varepsilon)=E V_{t}
$$

where $E V_{t}$ is given by equation (6). In general this involves solving a non-linear equation. 
Trajtenberg (1990) proposes approximating this, somewhat difficult to compute quantity, by the value computed in equation (6) divided by the average price level in period $t-1$. Finally, the above discussion was cast in terms of price changes but it can easily be used to treat other economic changes, for example introduction of new brands or a change in the quality of existing brands.

There are two other measures of welfare that are commonly used. The first is a price index based on so called index formulas. The basic idea is to summarize many prices into a single index, which tries to measure the average price increase. Different weights, used to average across products, will yield different indexes. For example, the quantities consumed in periods $t$ or $t+1$ are a common choices for weights. Below I present one such price index as a preliminary analysis of the data. ${ }^{5}$

The second approach is a quantity index. The intuition behind this index is that of revealed preference. For example, given the prices in $t+1$ is the bundle consumed in $t$ affordable? If so, and if it was not chosen, then the consumer is (revealed preferred to be) better off. This means that one can use the prices in $t+1$ to average across quantities in both periods to construct a (revealed preference) quantity index. As in the case of a price index, there are many choices for the weights used to average the quantities. Below I present and discuss one such choice.

\subsection{Two Key Assumptions}

Whether we are interested in the aggregate EV, or some other statistic, and regardless of whether this statistic is computed analytically or by simulation, there are two assumptions that have to be made. (1) What has happened to the utility from the outside good between the two periods? (2) What is captured by the unobserved characteristics, $\xi_{j}^{t}$, and do these characteristics change between the two periods?

When estimating the model previously described we cannot separately identify a change in

\footnotetext{
${ }^{5}$ See Diewert (2001), and references therein, for various ways of constructing and deriving such an index, the correspondence between these measures and EV, as well as various other issues in constructing an index number. It is important to note that the issues raised here are implicitly present in these price indexes. The structure of the model used here allows us to discuss the issues.
} 
the utility from the outside option from a change in the mean utility of the inside goods. For example we cannot distinguish between an increase in the desirability of the inside goods from a decrease in the utility of the outside good. These two effects have opposite implications for consumer welfare. If the inside goods have improved then consumer welfare increased, while if the quality of outside good deteriorated then consumer welfare decreased.

This identification problem is not unique to the discrete choice model. For example consider the case where a time dummy variable is included in a demand system. A positive coefficient on this time dummy variable implies an outward shift in the demand curve which can be a result of two different reasons. A decrease in the quality of alternative products, which implies a decrease in overall welfare, or an increase in the quality of the product being considered, which implies an increase in overall welfare. If the demand for the alternative commodities is modeled then the changes in utility from these alternative products will be captured by the change in their demand curves. However, in practice we are never able to include all alternatives in the demand system.

A different problem is that the utility given in equation (1), required to compute the integral in equation (5), includes the unobserved product characteristics, $\xi_{j}^{t}$. By definition the unobserved characteristics include all variables that are not included in the model just like the error-term in a classical demand system. Indeed in the estimation this variable will be the error-term, and therefore it can be recovered as the residual. If we use data from both periods $t$ and $t$ - 1 to estimate the model, then in general we will have two different values of $\xi_{j}^{t}$ for products that were present in both periods. Which values of $\xi_{j}^{t}$ should we use for the welfare analysis? Should we use the same value in both periods?

The answers depend on what we believe is included in the unobserved components. If these components are merely unobserved product characteristics, and a change in them is a quality change, then one would want to let them vary over time. On the other hand, if changes in these components capture taste changes (in the sense of Fisher and Shell, 1972) we would like to hold them fixed. In reality the unobserved components include both aspects, but which is more important depends on the case being analyzed, and cannot be identified without additional information. 
If one is able to include many observed physical characteristics in the demand model it is tempting to hold the residual, $\xi_{j}^{t}$, fixed in the welfare analysis. However, if new options are introduced $\xi_{j}^{t}$ plays an additional role, which is best explained by an example. Consider the following situation: ${ }^{6}$ consumers choose between driving their car to work or taking the red bus (for simplicity assume that working at home is not an option and that the decision of whether to work or not does not depend on the mode of transportation). Half the consumers choose a car and half choose the red bus. Now suppose we artificially introduce a new option: a blue bus. This option is artificial because consumers do not care about the color of the bus and in their eyes the red and blue buses are identical. Abstracting away from any competitive effects (suppose prices are regulated), the introduction of this supposedly new option will result in an equilibrium where half the consumers choose a car, and the rest are evenly split between the two color buses. Consumer welfare has not changed.

Suppose a researcher wants to use the Logit model to analyze the consumer welfare generated by the introduction of the blue bus. If data from before and after the introduction is observed the question of whether $\xi_{j}^{t}$ should be allowed to change becomes relevant. Normalize the marginal utility of income, $\alpha$, to 1 , and $V_{i, c a r}^{t}=V_{\text {car }}^{t}=0$. Then $V_{\text {red }}^{t}=\log \left(S_{\text {red }}^{t}\right)-\log \left(S_{\text {car }}^{t}\right)=0$, where $S_{j}^{t}$ denotes the (observed) share of the population that choose option $j$ at time $t$. Since we assumed no change in any of the characteristics, or in price, the only potential change between $t$ and $t+1$ (i.e., with or without the new option) is the change in the unobserved components. If these are held fixed then $V_{\text {car }}^{t+1}=V_{\text {red }}^{t+1}=V_{\text {blue }}^{t+1}=0$ and the change in consumer welfare, given by equation (6), is $(\log (3)-\log (2)) / 1$, which is positive. If we allow the unobserved components to vary then $V_{\text {red }}^{t+1}=\log \left(S_{\text {red }}^{t+1}\right)-\log \left(S_{\text {car }}^{t+1}\right)=\log (0.5)=V_{\text {blue }}^{t+1}$ and the change in consumer welfare is 0 .

This example demonstrates several things. First, it shows that when new options are introduced the unobserved components are not merely unobserved physical characteristics. There is no physical difference between the bus option pre-introduction and the reb/blue options post

\footnotetext{
${ }^{6}$ This example is the well-known red bus/blue bus problem introduced by Debreu (1960).
} 
introduction, yet in order to obtain the right answer we had to assume that the unobserved components changed. Second, this example suggests at least one situation in which allowing the $\xi_{j}^{t}$ to vary is a good idea: if the brand being introduced is a good (perfect) substitute for previously existing products. Note, that the amount of the change was not arbitrary: it was computed from the observed market shares post introduction.

The distinction made here between the time trend and the error terms is somewhat artificial. They both stem from the same problem: we do not know what is the unobserved term. The time trend just removes the trend from the unobserved term, which helps with the estimation, but does not solve the problem of interpretation. The reason I separate the two is to stress that the problem applies to all components of the model that are not fully specified, whether or not they are part of the econometric error term.

\section{AN EMPIRICAL EXAMPLE}

This section demonstrates the use of the methodology presented in the previous section to welfare analysis of price and quality changes, and brand introduction in the ready-to-eat (RTE) cereal industry. I use the data described in the Appendix to estimate the demand for cereal using a random coefficients discrete choice model. Next, I use the estimated demand system to evaluate the welfare gains in this industry over the period considered.

\subsection{Trends in the Ready-to-Eat Cereal Industry}

Ready-to-eat cereal was first introduced roughly 135 years ago. Initially it was mainly used to provide a healthy breakfast at various health resorts (the most well-known was the one run by Dr. John Harvey Kellogg). It was not before long that the popularity of breakfast cereal spread beyond this limited use. The sales of RTE cereals grow at a steady $3 \%$ annual rate in the post war era. In 1997 the U.S. market consumed approximately 3 billion pounds of cereal, grossing roughly $\$ 9$ billion in sales.

The driving force behind this growth was the successful introduction of new products. The 
number of new brands introduced by the top six manufacturers (Kellogg, General Mills, Post, Quaker, Ralston, and Nabisco) increased dramatically over time. In the peak year, 1988, more brands were introduced than in the decade of 1950-1959. Starting from 1989 the level of introductions declined and matched the levels of the early 80 's.

During the period 1988-1992, of increased brand introductions, the price of cereal rose significantly. Table 1 presents various price indexes. The first two columns present the Consumer Price Index (CPI) and the change in the price of food and beverage. Both series are taken from the BLS. The next six columns present price indexes computed from the data used in the estimation below. The column labeled " 24 Cereal Brands" computes a fixed weights index for the 24 products that are present in all time periods. ${ }^{7}$ As mentioned in Section 2.2 this type of a price index tries to summarize the "average" price increase. Indeed the average price went up and loosely speaking consumers should be worse off.

In order to complete the picture Table 2 presents quantity indexes, computed from the data described in the Appendix. The indexes are computed as the per capita pounds consumed relative to the per capita pounds consumed in the first quarter of 1988. As was noted above, these indexes could be considered a revealed preference index: if consumers consume more cereal they are better off, in a revealed preference sense. The most striking feature when comparing Tables 1 and 2 is that despite a nominal price increase the per capita consumption of cereal increases. For example, in the second quarter of 1989 the weighted average price of the 24 brands went up, relative to the last quarter of 1988 (106.7 vs. 103.7), but at the same time so did the quantity index (95.8 vs. 88.4). Consumers could be consuming more because the quality of cereal has gone up, and therefore despite the higher prices they are better off. Alternatively, they could be consuming more because the alternative, the outside good, is worse and therefore they are hurt by the price increase. Depending on the interpretation we should put more weight on either the price or quantity index as an indicator of consumer welfare. In a sense it is the relative importance placed on the "revealed

\footnotetext{
${ }^{7}$ I used as weights the base period quantities. There are numerous other alternatives one could use, but since the indexes are given only for descriptive purposes I do present these.
} 
preference" quantity index, which states that consumers are roughly no worse off, versus the price index, which states that consumers are strictly worse off, that will explain some of the results we observe below.

\subsection{The Estimated Demand System}

The first step of the analysis described in the previous section is estimation of demand. The empirical model described in Section 2.1 was used. The instrumental variables include average regional prices in all quarters and the cost proxies discussed in the Appendix. The results presented here are taken from Nevo (2001), see there for a detailed discussion. Here I focus only on the main results. ${ }^{8}$

The results of the estimation are presented in Table 3. The first column displays the means of the taste parameters, $\alpha$ and $\beta$. Generally speaking the coefficients seem to have the expected signs. The next five columns present the parameters that measure heterogeneity in the population: standard deviations, interaction with log of income, log of income squared, log of age, and a dummy variable that is equal to one if age is under sixteen. The estimates of standard deviations of the taste parameters are non-significant at conventional significance levels for all characteristics except for the Kids segment dummy variable. Most interactions with demographics are significant. Marginal utility from sugar decreases with income. Marginal valuation of sogginess increases with income. In other words, wealthier (and possibly more health conscious) consumers are less sensitive to the crispness of a cereal.

The estimated time dummy variables (not displayed in the table) show a positive trend with

\footnotetext{
${ }^{8} \mathrm{My}$ goal in this section is to demonstrate the empirical importance of the assumptions previously discussed. Therefore, I will not argue here for the validity of the identifying assumptions, the data construction and the modeling assumptions (see Nevo, 2001, for such arguments). All that I claim here is that the estimated demand system is "reasonable," in the sense that using the estimates to demonstrate the effects of the assumptions is meaningful.
} 
usually lower demand in the fourth quarter. ${ }^{9}$ The interpretation of this trend will be a focus of the next section. An additional focus will be on interpreting the change in the residuals. The average of $\xi_{j}^{t}-\xi_{j}^{t-1}$ is zero with a standard deviation of 0.67 and $90 \%$ of the distribution between -1.1 and 1.1. This is roughly of the same order of magnitude as the estimated time dummy variables, so at least in principle it is not clear which of the two assumptions previously discussed would have a greater impact.

Further discussion of the results and their implications, including price elasticities and implied markups, can be found in Nevo (2001).

\subsection{Welfare Gains}

Equivalent variations are presented in Table 4. For each set of assumptions two series of equivalent variations are computed: those using the full model and a BLS-like measure. The columns labeled Full are computed by multiplying the population weighted average of the median EV in each city, by 260 million (the US population) and 365 days. The median EV in a city was used so to reduce the impact of outliers. ${ }^{10}$ The results were multiplied by the number of days because the "product" is defined as one serving of cereal per capita per day. Therefore, in order to convert the welfare gain into annual welfare gains we need to multiply by the number of choices made, i.e., the number of days. Since this is a per capita measure it is multiplied by the US population in order to obtain the aggregate measure.

The columns labeled $B L S$ display a BLS-like measure. The BLS price index uses fixed base-

\footnotetext{
${ }^{9}$ The time dummy variables could be picking up changes in income over time. These changes should, in principle, be captured by the model since income can impact choice (see footnote 1). In reality, however, since household data is not observed this effect can be masked by simulation error. Nevo (2001) went to some length to insure this was not the case. Here I also examined a specification that included the average income by market. The results are essentially identical.

${ }^{10}$ I also explored eliminating the effects of outliers by taking the average EV of all individuals excluding the top and bottom 5\%, or by averaging only over individuals with EV within two standard deviations away from the city mean. Admittedly, all these solutions are very ad-hoc. As pointed out by Petrin (1998), one has to be sure that the welfare results are not driven by the behavior in the tails. Since this point is somewhat orthogonal to the point I am making here, I focus on measures that are not driven by the behavior in the tails of the distribution, rather than offering a general solution.
} 
year weights. The equivalent in our framework is to assume that the individual probabilities of purchase of each product do not change, but that the conditional indirect utility obtained from a product does (Pakes, Berry and Levinsohn, 1993) . For each individual this quantity is computed by substituting into the integral in equation (6) the difference in utility relative to the base-year, rather than the welfare derived from a given choice set. Once again the median for each city was multiplied by the US population and the number of days.

The two measures were computed under different assumptions on what is a change in utility versus what is a change of tastes. As was discussed in Section 2, the "error" in the regression, $\xi_{j}^{t}$, is the perceived quality of the product (i.e., the level of utility needed to rationalize the observed purchased quantities.) A change in this variable can be either considered a change in tastes or a change in the utility consumers obtain from the product. ${ }^{11}$ There is nothing in the data or the basic model to separate these two interpretations. Rather than making additional assumptions the results in Table 4 examine the two extreme cases. The columns labeled $\xi_{j}^{t}$ Change assume utility from the product changes, while the columns labeled $\xi_{j}^{t}$ Fixed attribute the change in the perceived quality to a change in tastes and therefore fix the value of $\xi_{j}^{t}$ at its base-year value.

The first four columns attribute all the change over time to changes in the valuation of the outside good. As was discussed in Section 2 this is equivalent to not including time dummies in the computation. In contrast, the last four columns attribute the change in the time dummies to increases in the utility of the "inside" products. ${ }^{12}$ The actual changes over time are probably a combination of both these effects, but the data cannot separate which part is due to which effect.

Comparing across the different set of assumptions the equivalent variations vary significantly. This is seen even more dramatically when we examine the price index, computed as described in Section 2 and presented in Table 5. The estimates range from a 35.6\% increase in prices

\footnotetext{
${ }^{11}$ An alternative is to assume that this captures the effects of variables that influence choice but not utility. This requires a separation between choice and utility. Thus, fundamentally undermining the foundation of the revealed preference approach to consumer welfare.

${ }^{12}$ All the columns are based on the same estimation results, which includes time dummies, the difference is only in the interpretation of the results.
} 
to a $2.4 \%$ decrease in prices. This range should not be surprising given the difference between the price and quantity indexes presented above. The different set of assumptions sort out the rise in prices and slight rise (or no change) in quantities by attributing them to different causes. For example, the columns that assume the utility from the outside good is fixed, attribute more weight to the "revealed preference" quantity index and since consumption is roughly constant even though prices increase consumer welfare has not decreased.

For the data used here the more important of the two assumptions is the one regarding the change in the utility of the outside good (which is just the allocation of the time dummy variables). There is no reason why this should always be the case. In particular there are several issues that make this example unique. First, there is fairly little product or quality improvements in ready-to-eat cereal. The picture might be different if we examine other products like computers or automobiles. Second, the analysis here was limited to a small set of well established products. The relative importance of the two assumptions might differ if we include more new products.

There are a variety of intermediate assumptions one could make of how to attribute the time effects into changes in the inside goods versus a change in the outside good. One such assumption is used by Pakes, Berry and Levinsohn (1993), who assume that on average the unobserved quality of continuing products is the same. With a nearly fixed set of products, like I have here, this is almost equivalent to the columns that allow the utility from the outside good to change (if the set of products was exactly fixed this would be exactly equal). An alternative assumption is exploited in the middle columns of Table 5. Here I assume the utility from the outside good varies with the Consumer Price Index. ${ }^{13}$ For the data used here this yields results similar to splitting the time effect equally between the inside and outside goods.

The columns labeled $B L S$ in Tables 4 and 5 display, for each set of assumptions, the results from the suggested measure holding the set of products and the purchasing probabilities fixed at the first value of 1988 values. In general the results in these columns vary like those from the full

\footnotetext{
${ }^{13}$ In some sense this is cheating. If the purpose of the analysis is to compute a CPI than I cannot use it in order to generate the results.
} 
model, when compared across different assumptions. For a given set of assumptions the difference between the Full and BLS columns includes the bias due to using a fixed set of weights and the exclusion of new products. The latter seems to have a greater effect. The only new product in the sample is Post Honey Bunches of Oats, which was introduced in the second quarter of 1989. This is also the first point were the two columns start to differ systematically. Note also that this difference might over-estimate the bias due to new products because it does not allow for the disappearance of products. In principle one could try to separate the various effects that contribute to this difference by using a model like that suggested by Hausman (1996).

\section{DISCUSSION}

This paper discusses the use of estimated brand level demand systems to construct a price index. I use a discrete choice model to point out two key assumptions regarding (1) the interpretation of the changes over time in the average demand for all products considered; and (2) the interpretation of a change in the unobserved components effecting demand for each product. Neither of these points is specific to the discrete choice model. Data from the ready-to-eat cereal industry is used to demonstrate the empirical importance of the assumptions. For this data set the breakdown of the time trend (i.e., the average change of all products) was more important than the interpretation of the brand-specific unobserved component.

Where do these results leave us? I hope that it would become common practice at the very least to do two things. First, clearly state the assumptions made and provide justification why these are the "correct" assumptions for the case being considered. Unfortunately, I do not believe that the various issues could be resolved on theoretical grounds; therefore, reporting the range of the impact of the assumptions, as presented in Tables 4 and 5, would help. Hopefully in some cases the sensitivity to the assumptions would be smaller than the example provided here.

In those cases where the range will not be tight, more care should be placed on some of the details. For example, the effect of alternatives (the changes in the outside good) might be reduced by including more products in the analysis. Even if this does not impact the estimated demand 
system it could ease the interpretation of the results. Placing more structure on the unobserved components of demand, and their evolution over time, is another way in which additional information can be incorporated into the analysis.

While the results of this paper are mainly negative, they have implications on the direction of future work. The results suggest that certain parts of the model that can be left unspecified, if the main focus is the matrix of cross-price elasticities (or its implications), have to be better characterized for welfare analysis. One such characterization is given by Berry, and Pakes (1999), who rather than leaving the unobserved quality as a residual model how it evolves. The performance of this new method and its sensitivity to the above assumptions is yet unknown.

As mentioned above the assumptions discussed here are not unique to the discrete choice model, they are present in other demand models as well. Furthermore, some of the same issues also arise when computing a price index using an index formula. For example, Triplett (1998) reports that using data from the Canadian soft-drinks market Shultz (1994) finds that prices indexes computed from 6 different index formulas yield a range of 15.1 to 925.7, over a range of five years. While not directly comparable to the range we find here, it does make the range I report seem tight.

A somewhat different use of an economic model to predict the welfare changes due to an economic event has recently been used by Hausman $(1996,1997)$ and Petrin (1998). They both examine the welfare implications of new brand introductions. The essential idea is to use an economic model of demand and supply to produce the counterfactual of what the market equilibrium would have looked like in the absence of the new product. With this prediction in hand one could compare consumer welfare in these two outcomes. This approach is valid if the subject of research is an isolated event (e.g., an introduction of a new product, a merger or a change in regulatory environment), which can be modeled. In such a case this approach partly side steps the problems discussed here. Since the purpose of the analysis is to produce a counterfactual for a particular observed outcome no assumptions have to be made regarding the interpretation of time effects. Although if one would like to link these effects into a price index the problem is reintroduced. Also a natural assumption to make with regards to the unobserved characteristics is that they do not vary. 
This assumption implies that the only reaction to the brand introduction is in prices and not in other decision variables that enter the error-term. For example, if a reaction to a brand introduction would be a change in promotion activity or a change in the unobserved characteristics then this assumption will be violated.

\section{REFERENCES}

Berry, S. (1994), "Estimating Discrete-Choice Models of Product Differentiation," Rand Journal of Economics, 25, 242-262.

Berry, S., J. Levinsohn, and A. Pakes (1995), "Automobile Prices in Market Equilibrium," Econometrica, 63, 841-890.

Berry, S., and A. Pakes (1999), "Estimating the Pure Hedonic Discrete Choice Model," Yale University, mimeo.

Boskin M.J., E.R. Dulberger, R.J. Gordon, Z. Griliches, and D. Jorgenson (1996), “Toward a More Accurate Measure of the Cost of Living," Final Report to the Senate Finance Committee from the Advisory Commission To Study The Consumer Price Index, December 4.

Diewert, E. W. (2001), "The Consumer Price Index and Index Number Theory: A Survey," Discussion Paper No 01-02, Department of Economics, University of British Columbia.

Gordon, R. J. and Z. Griliches (1997), "Quality Changes and New Products,” American Economic Review, 87(2), 84-88.

Fisher, F. and K. Shell (1972), The Economic Theory of Price Changes: Two Essays on the Effects of Taste Quality and Technological Change, New York: Academic Press.

Hausman, J. (1996), "Valuation of New Goods Under Perfect and Imperfect Competition,"in T. Bresnahan and R. Gordon, eds., The Economics of New Goods, Studies in Income and Wealth Vol. 58, Chicago: National Bureau of Economic Research.

Hausman, J.(1997),"Valuing the Effects of Regulation on New Services in Telecommunications," Brookings Papers on Economic Activity, Microeconomics.

Hicks, J.R. (1939), Value and Capital, Oxford: Clarendon Press. 
Mas-Colell, A., M. Whinston and J. Green (1995), Microeconomic Theory, Oxford University Press. McFadden, D. (1981), "Econometric Models of Probabilistic Choice," in C. Manski and D. McFadden, eds., Structural Analysis of Discrete Data, pp. 198-272, Cambridge: MIT Press. McFadden, D. (1995), “Computing Willingness-to-Pay in Random Utility Models,” University of California, Berkeley, mimeo (available from http://emlab.berkeley.edu/ mcfadden).

Nevo, A. (2000), “A Practitioner's Guide to Estimation of Random Coefficients Logit Models of Demand," Journal of Economics \& Management Strategy, 9(4), 513-548.

Nevo, A. (2001), "Measuring Market Power in the Ready-to-Eat Cereal Industry," Econometrica, 69(2), 307-342.

Pakes, A., S. Berry, and J. Levinsohn (1993), "Applications and Limitations of Some Recent Advances in Empirical Industrial Organization: Price Indexes and the Analysis of Environmental Change," American Economic Review, Papers and Proceedings, 83, 240-246.

Petrin, A. (1998), “Quantifying the Benefits of New Products: The Case of the Minivan," University of Chicago, mimeo.

Schultz, B. (1994), "Choice of Price Index Formula at the Micro-Aggregation Level: The Canadian Empirical Evidence," in International Conference on Price Indices: Papers and Final Report. First Meeting of the International Working Group on Price Indices.

Small, K. A., and H. S. Rosen, (1981), “Applied Welfare Analysis with Discrete Choice Models," Econometrica, 49, 105-30.

Trajtenberg, M. (1989), “The Welfare Analysis of Product Innovations, with an Application to Computed Tomography Scanners," Journal of Political Economy, 97, 444-79.

Trajtenberg, M. (1990), Economic Analysis of Product Innovation: The Case of CT Scanners, Cambridge, MA: Harvard University Press.

Triplett, J. E. (1998), “Elementary Indexes for a Consumer Price Index,” Brookings Institute. 


\section{DATA AND ESTIMATION APPENDIX}

Data

Market shares and prices were obtained from the IRI Infoscan Data Base at the University of Connecticut. These data were collected by Information Resources, Inc. (IRI), a marketing firm in Chicago, using scanning devices in a national random sample of supermarkets located in various size metropolitan areas and rural towns. These data are aggregated by brand (for example different size boxes are considered one brand), city and quarter. The data covers up to 65 different cities, and ranges from the first quarter of 1988 to the last quarter of 1992. The results presented are computed using the 25 brands with the highest national market shares in the last quarter of 1992 (detailed in the Table A1). For all, except one, there are 1124 observations (i.e., they are present in all quarters and all cities). The exception is Post Honey Bunches of Oats, which appears in the data only in the second quarter of 1989. The combined city-level market share of the brands in the sample varies between 43 and 62 percent of the total volume of cereal sold in each city and quarter. Combined national market shares vary between 55 and 60 percent.

Market shares are defined by converting volume sales into number of servings sold (using the manufacturers suggested serving size), and dividing by the total potential number of servings in a city in a quarter. This potential was assumed to be one serving per capita per day. The outside good market share was defined as the residual between one and the sum of the observed market shares. A price variable was created by dividing the dollar sales by the number of servings sold, and was deflated using a regional urban consumers CPI. The dollar sales reflect the price paid by consumers at the cashier, generating an average real per serving transaction price. However, the sales data does not account for any coupons used post purchase.

The Infoscan data was matched with a few other sources. First, advertising data was taken from the Leading National Advertising data base, which contains quarterly national advertising expenditures by brand collected from 10 media sources. ${ }^{14}$ I used only the total of the 10 types of media. Product characteristics were collected in local supermarkets by examining cereal boxes. This implicitly assumes that the characteristics have not changed since 1988. Although this is not exactly true, it seems a reasonable first approximation. Each cereal was classified into "mushy" or not, depending on its sogginess in milk. ${ }^{15}$ There might be some measurement error in this classification. Information on the distribution of demographics was obtained by sampling individuals from the March Current Population Survey for each year. Individual income was obtained by dividing household income by the size of the household. Finally, instrumental variables were constructed using two additional data sources. An average of wages paid in the supermarket sector in each city was constructed from the NBER CPS Monthly Earning Extracts. Estimates of city density were taken from the BLS, as were regional price indices.

Summary statistics for all variables are displayed in Table A2.

\section{Estimation}

I estimate the parameters of the model described in Section 2 using the data described in the previous section by following the Berry (1994) and Berry, Levinsohn, and Pakes (1995) method.

\footnotetext{
${ }^{14}$ The sources include: magazines, Sunday magazines, newspapers, outdoor, network television, spot television, syndicated television, cable networks, network radio and national spot radio.

${ }^{15}$ I wish to thank Sandy Black for suggesting this variable and helping me classify the various brands.
} 
The key point of the estimation is to exploit a population moment condition that is a product of instrumental variables and a (structural) error term, to form a (non-linear) GMM estimator (for details see Berry, 1994; Berry, Levinsohn and Pakes, 1995). The error term is defined as the cityquarter specific unobserved product characteristics, $\xi_{j}^{t}$ (the estimation includes a brand fixed effect, which captures the overall mean of each brand's unobserved component). As instrumental variables I use the average price of the brand in other cities in the same region, as well as city level cost proxies. These instrumental variables are justified and examined carefully in Nevo (2001). The market share function is computed by assuming an i.i.d. extreme value distribution for $\varepsilon_{i j}^{t}$, a normal distribution with a diagonal variance matrix for $\tau_{i}$, and the empirical distribution of demographics $D_{i}$ as approximated by draws from the March CPS for each year. The extreme value distribution was integrated analytically, while the normal and empirical distribution were approximated by 40 individuals per market. For more details on the estimation, including computer code, see Nevo (2000). 
TABLE 1

PRICE INDEXES (88Q1=100)

\begin{tabular}{lcccccccc}
\hline \hline $\begin{array}{c}\text { Year } \\
\text { and } \\
\text { Quarter }\end{array}$ & CPI & $\begin{array}{c}\text { Food } \\
\text { \& } \\
\text { Beverage }\end{array}$ & $\begin{array}{c}\text { 24 } \\
\text { Cereal } \\
\text { Brands }\end{array}$ & $\begin{array}{c}\text { K } \\
\text { Corn } \\
\text { Flakes }\end{array}$ & $\begin{array}{c}\text { K } \\
\text { Frosted } \\
\text { Flakes }\end{array}$ & $\begin{array}{c}\text { GM } \\
\text { Cheerios }\end{array}$ & $\begin{array}{c}\text { Post } \\
\text { Raisin } \\
\text { Bran }\end{array}$ & $\begin{array}{c}\text { N } \\
\text { Shredded } \\
\text { Wheat }\end{array}$ \\
\hline 88Q2 & 101.3 & 101.1 & 101.3 & 102.8 & 101.5 & 101.3 & 100.6 & 101.5 \\
88Q4 & 103.7 & 103.8 & 107.5 & 109.5 & 107.2 & 109.6 & 107.2 & 107.8 \\
89Q2 & 106.7 & 107.7 & 112.3 & 115.1 & 113.2 & 112.0 & 107.2 & 113.9 \\
89Q4 & 108.5 & 109.4 & 117.5 & 114.7 & 118.3 & 119.7 & 116.4 & 113.3 \\
90Q2 & 111.4 & 113.2 & 120.5 & 119.9 & 119.7 & 125.5 & 119.6 & 118.1 \\
90Q4 & 115.3 & 115.5 & 125.1 & 118.4 & 122.5 & 130.3 & 116.2 & 124.3 \\
91Q2 & 116.9 & 118.6 & 127.6 & 119.5 & 123.8 & 130.1 & 121.1 & 132.0 \\
91Q4 & 118.8 & 118.2 & 129.2 & 118.0 & 119.0 & 133.3 & 121.3 & 147.1 \\
92Q2 & 120.4 & 119.4 & 128.8 & 110.5 & 117.4 & 138.3 & 123.3 & 154.1 \\
92Q4 & 122.4 & 120.1 & 132.4 & 121.5 & 122.9 & 137.9 & 124.8 & 160.3 \\
\hline
\end{tabular}

Source: IRI Infoscan Data Base, University of Connecticut, Food Marketing Center, and BLS series.

TABLE 2

QUANTITY INDEXES $(88 \mathrm{Q} 1=100)$

\begin{tabular}{lcccccc}
\hline \hline $\begin{array}{c}\text { Year and } \\
\text { Quarter }\end{array}$ & $\begin{array}{c}\text { 24 Cereal } \\
\text { Brands }\end{array}$ & $\begin{array}{c}\text { K Corn } \\
\text { Flakes }\end{array}$ & $\begin{array}{c}\text { K Frosted } \\
\text { Flakes }\end{array}$ & $\begin{array}{c}\text { GM } \\
\text { Cheerios }\end{array}$ & $\begin{array}{c}\text { Post Raisin } \\
\text { Bran }\end{array}$ & $\begin{array}{c}\text { N Shredded } \\
\text { Wheat }\end{array}$ \\
\hline 88Q2 & 99.9 & 98.8 & 95.3 & 92.8 & 99.7 & 106.3 \\
88Q4 & 88.4 & 84.1 & 81.9 & 90.9 & 71.2 & 92.5 \\
89Q2 & 95.8 & 96.2 & 97.7 & 108.0 & 78.4 & 85.5 \\
89Q4 & 88.5 & 94.1 & 83.2 & 98.5 & 57.7 & 73.7 \\
90Q2 & 99.7 & 97.4 & 94.0 & 106.5 & 59.7 & 78.2 \\
90Q4 & 95.9 & 106.3 & 101.0 & 95.8 & 70.1 & 73.0 \\
91Q2 & 103.0 & 111.2 & 93.2 & 116.0 & 74.5 & 72.9 \\
91Q4 & 98.9 & 110.3 & 100.3 & 103.1 & 73.9 & 61.4 \\
92Q2 & 106.0 & 120.9 & 106.2 & 120.1 & 77.8 & 68.1 \\
92Q4 & 97.1 & 83.0 & 89.2 & 121.8 & 83.2 & 71.1 \\
\hline
\end{tabular}

Source: IRI Infoscan Data Base, University of Connecticut, Food Marketing Center. 
TABLE 3

ESTIMATED DEMAND PARAMETERS

\begin{tabular}{|c|c|c|c|c|c|c|}
\hline \multirow[t]{2}{*}{ Variable } & \multirow{2}{*}{$\begin{array}{c}\text { Means } \\
\left(\beta^{\prime} s\right)\end{array}$} & \multirow{2}{*}{$\begin{array}{l}\text { Standard } \\
\text { Deviation } \\
\left.\text { s ( } \sigma^{\prime} s\right)\end{array}$} & \multicolumn{4}{|c|}{ Interactions with Demographic Variables: } \\
\hline & & & Income & Income $\mathrm{Sq}$ & Age & Child \\
\hline Price & $\begin{array}{c}-27.198 \\
(5.248)\end{array}$ & $\begin{array}{c}2.453 \\
(2.978)\end{array}$ & $\begin{array}{c}315.894 \\
(110.385)\end{array}$ & $\begin{array}{c}-18.200 \\
(5.914)\end{array}$ & - & $\begin{array}{c}7.634 \\
(2.238)\end{array}$ \\
\hline Advertising & $\begin{array}{c}0.020 \\
(0.005)\end{array}$ & - & - & - & - & - \\
\hline Constant & $\begin{array}{l}-3.592 \\
(0.138)\end{array}$ & $\begin{array}{c}0.330 \\
(0.609)\end{array}$ & $\begin{array}{c}5.482 \\
(1.504)\end{array}$ & - & $\begin{array}{c}0.204 \\
(0.341)\end{array}$ & - \\
\hline Cal from Fat & $\begin{array}{c}1.146 \\
(0.128)\end{array}$ & $\begin{array}{c}1.624 \\
(2.809)\end{array}$ & - & - & - & - \\
\hline Sugar & $\begin{array}{c}5.742 \\
(0.581)\end{array}$ & $\begin{array}{c}1.661 \\
(5.866)\end{array}$ & $\begin{array}{c}-24.931 \\
(9.167)\end{array}$ & - & $\begin{array}{c}5.105 \\
(3.418)\end{array}$ & - \\
\hline Mushy & $\begin{array}{l}-0.565 \\
(0.052)\end{array}$ & $\begin{array}{c}0.244 \\
(0.623)\end{array}$ & $\begin{array}{c}1.265 \\
(0.737)\end{array}$ & - & $\begin{array}{c}0.809 \\
(0.385)\end{array}$ & - \\
\hline Fiber & $\begin{array}{c}1.627 \\
(0.263)\end{array}$ & $\begin{array}{c}0.195 \\
(3.541)\end{array}$ & - & - & - & $\begin{array}{c}-0.110 \\
(0.0513)\end{array}$ \\
\hline All-family & $\begin{array}{c}0.781 \\
(0.075)\end{array}$ & $\begin{array}{l}0.1330 \\
(1.365)\end{array}$ & - & - & - & \\
\hline Kids & $\begin{array}{c}1.021 \\
(0.168)\end{array}$ & $\begin{array}{c}2.031 \\
(0.448)\end{array}$ & - & - & - & \\
\hline Adults & $\begin{array}{c}1.972 \\
(0.186)\end{array}$ & $\begin{array}{c}0.247 \\
(1.636)\end{array}$ & -- & -- & - & \\
\hline GMM Object & (degrees & freedom) & $5.05(8)$ & & & \\
\hline
\end{tabular}

Based on 27,862 observations. Except where noted, parameters are GMM estimates. All regressions include brand and time dummy variables. Asymptotic robust standard errors are given in parenthesis. 
TABLE 4

EQUIVALENT VARIATION

(millions of $19881^{\text {st }}$ quarter dollars per year)

\begin{tabular}{|c|c|c|c|c|c|c|c|c|}
\hline \multirow{3}{*}{$\begin{array}{c}\text { Year } \\
\text { and } \\
\text { Quarter }\end{array}$} & \multicolumn{4}{|c|}{ Utility from Outside Good Changes } & \multicolumn{4}{|c|}{ Utility from Outside Good Fixed } \\
\hline & \multicolumn{2}{|c|}{$\xi_{\mathrm{jt}}$ Change } & \multicolumn{2}{|c|}{$\xi_{\mathrm{jt}}$ Fixed } & \multicolumn{2}{|c|}{$\xi_{\mathrm{jt}}$ Change } & \multicolumn{2}{|c|}{$\xi_{\mathrm{jt}}$ Fixed } \\
\hline & Full & BLS & Full & BLS & Full & BLS & Full & BLS \\
\hline $88 \mathrm{Q} 2$ & 32 & -97 & -22 & -29 & 88 & -45 & 26 & 21 \\
\hline 88Q4 & -342 & -454 & -370 & -383 & -52 & -142 & -47 & -58 \\
\hline $89 \mathrm{Q} 2$ & -884 & -1258 & -1004 & -1408 & 242 & -66 & 120 & -81 \\
\hline $89 \mathrm{Q} 4$ & -862 & -1240 & -890 & -1233 & -1 & -353 & -79 & -307 \\
\hline 90Q2 & -1835 & -2121 & -1580 & -2110 & 135 & -74 & 320 & 13 \\
\hline 90Q4 & -1469 & -1741 & -1359 & -1789 & 72 & -209 & 110 & -123 \\
\hline 91Q2 & -2234 & -2612 & -2013 & -2508 & 230 & -57 & 407 & 64 \\
\hline 91Q4 & -1785 & -2059 & -1546 & -2056 & 60 & -180 & 256 & -78 \\
\hline $92 \mathrm{Q} 2$ & -1669 & -2112 & -1319 & -1938 & 97 & -143 & 430 & 4 \\
\hline $92 \mathrm{Q} 4$ & -1852 & -2270 & -1518 & -2104 & 112 & -160 & 406 & 36 \\
\hline
\end{tabular}

All measures are based on the results of Table 3. The columns labeled Full present results from the model, while the column labeled $B L S$ present a BLS-like measure. Different columns make different assumptions on the interpretation of the regression results (see text for details).

TABLE 5

PRICE INDEXES COMPUTED FROM THE MOdEL $(88 \mathrm{Q} 1=100)$

\begin{tabular}{|c|c|c|c|c|c|c|c|c|c|c|c|c|}
\hline \multirow[t]{3}{*}{$\begin{array}{l}\text { Year } \\
\text { and }\end{array}$} & \multicolumn{4}{|c|}{$\begin{array}{l}\text { Utility from Outside Good } \\
\text { Changes }\end{array}$} & \multicolumn{4}{|c|}{$\begin{array}{l}\text { Utility from Outside Good } \\
\text { Changes with the CPI }\end{array}$} & \multicolumn{4}{|c|}{$\begin{array}{l}\text { Utility from Outside Good } \\
\text { Fixed }\end{array}$} \\
\hline & \multicolumn{2}{|c|}{$\xi_{\mathrm{jt}}$ Change } & \multicolumn{2}{|c|}{$\xi_{\mathrm{jt}}$ Fixed } & \multicolumn{2}{|c|}{$\xi_{\mathrm{jt}}$ Change } & \multicolumn{2}{|c|}{$\xi_{\mathrm{jt}}$ Fixed } & \multicolumn{2}{|c|}{$\xi_{\mathrm{jt}}$ Change } & \multicolumn{2}{|c|}{$\xi_{\mathrm{jt}}$ Fixed } \\
\hline & Full & BI S & & & Full & & Full & & Full & & Full & $\mathrm{BL}$ \\
\hline & & & & & & & & & & & & \\
\hline & & & & & & & & & 00.3 & & 3 & 10 \\
\hline & & & & & & & & & & & & 100.5 \\
\hline & & & & & .5 & & .0 & & 100.0 & & 100.5 & 101 \\
\hline & & & & & & & & & 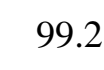 & & & 99.9 \\
\hline & & & & & & & & & 99.6 & & 99.4 & 100.7 \\
\hline & & & & & 3 & & & & 8.7 & & & 99.6 \\
\hline & & 1 & & & 4 & & & & 9.7 & & .5 & 100.5 \\
\hline & & 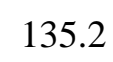 & & & 8 & & & & 91 & & .3 & 100.0 \\
\hline $2 \mathrm{Q} 4$ & 5.6 & 8.6 & 133.2 & 137.4 & 21.6 & 123.6 & 19.5 & 122.2 & 99.4 & 10 & 97. & 99. \\
\hline
\end{tabular}

All measures are based on the results of Table 3. The columns labeled Full present results from the model, while the column labeled $B L S$ present a BLS-like measure. Different columns make different assumptions on the interpretation of the regression results (see text for details). 
TABLE A1

BRANDS USED FOR ESTIMATING DEMAND

\begin{tabular}{|c|c|c|c|}
\hline $\begin{array}{c}\text { All Family/ } \\
\text { Basic Segment }\end{array}$ & $\begin{array}{c}\text { Taste Enhanced Wholesome } \\
\text { Segment }\end{array}$ & $\begin{array}{c}\text { Simple Health } \\
\text { Nutrition Segment }\end{array}$ & Kids Segment \\
\hline $\begin{array}{l}\text { K Corn Flakes } \\
\text { K Rice Krispies } \\
\text { K Crispix } \\
\text { GM Cheerios } \\
\text { GM Wheaties }\end{array}$ & $\begin{array}{l}\text { K Raisin Bran } \\
\text { K Frosted Mini Wheats } \\
\text { P Raisin Bran } \\
\text { P Honey Bunches of Oats } \\
\text { GM Raisin Nut } \\
\text { Q 100\% Natural }\end{array}$ & $\begin{array}{l}\text { K Special K } \\
\text { GM Total } \\
\text { P Grape Nuts } \\
\text { N Shredded Wheat }\end{array}$ & $\begin{array}{l}\text { K Frosted Flakes } \\
\text { K Froot Loops } \\
\text { K Corn Pops } \\
\text { GM H-N Cheerios } \\
\text { GM KIX } \\
\text { GM Lucky Charms } \\
\text { GM Trix } \\
\text { GM Cinn Toast Crunch } \\
\text { Q CapN Crunch } \\
\text { Q Life }\end{array}$ \\
\hline
\end{tabular}

$\mathrm{K}=$ Kellogg, GM = General Mills, $\mathrm{P}=$ Post, $\mathrm{Q}=$ Quaker Oats, $\mathrm{N}=$ Nabisco.

TABLE A2

SAMPLE STATISTICS

\begin{tabular}{lrrrrr}
\hline \multicolumn{1}{c}{ Description } & Mean & Median & Std & Min & Max \\
\hline Prices ( $\varnothing$ per serving) & 19.4 & 18.9 & 4.8 & 7.6 & 40.9 \\
Advertising (M\$ per quarter) & 3.56 & 3.04 & 2.03 & 0 & 9.95 \\
Share within Cereal Market (\%) & 2.2 & 1.6 & 1.6 & 0.1 & 11.6 \\
Calories & 137.6 & 120 & 36.32 & 110 & 220 \\
Fat Calories (/100) & 0.124 & 0.100 & 0.139 & 0 & 0.60 \\
Sodium (\% RDA/100) & 0.087 & 0.090 & 0.042 & 0 & 0.150 \\
Fiber (\% RDA/100) & 0.095 & 0.050 & 0.094 & 0 & 0.310 \\
Sugar (g/100) & 0.084 & 0.070 & 0.060 & 0 & 0.200 \\
Mushy (=1 if cereal gets soggy in milk) & 0.35 & -- & -- & 0 & 1 \\
Serving weight (g) & 35.1 & 30 & 9.81 & 25 & 58 \\
Income (\$) & 13,083 & 10,475 & 11,182 & 14 & 275,372 \\
Age (years) & 29.99 & 28 & 23.14 & 1 & 90 \\
Child (=1 if age<16) & 0.23 & -- & -- & 0 & 1 \\
\hline Sorce: IRI
\end{tabular}

Source: IRI Infoscan Data Base, University of Connecticut, Food Marketing Center, Cereal boxes and samples from the CPS. 